\title{
Cognitive style in bipolar disorder
}

\author{
LISA JONES, JAN SCOTT, SAYEED HAQUE, KATHERINE GORDON-SMITH, \\ JESSICA HERON, SIAN CAESAR, CAROLINE COOPER, LIZ FORTY, \\ SALLY HYDE, LOUISA LYON, JAYNE GREENING, PAK SHAM, ANNE FARMER, \\ PETER MCGUFFIN, IAN JONES and NICK CR ADDOCK
}

\section{Background Abnormalities of cognitive style in bipolar disorder are of both clinical and theoretical importance.}

\begin{abstract}
Aims To compare cognitive style in people with affective disorders and in healthy controls.
\end{abstract}

Method Self-rated questionnaires were administered to 118 individuals with bipolar I disorder, 265 with unipolar major recurrent depression and 268 healthy controls. Those with affective disorder were also interviewed using the Schedules for Clinical Assessment in

Neuropsychiatry and case notes were reviewed

Results Those with bipolar disorder and those with unipolar depression demonstrated different patterns of cognitive style from controls; negative selfesteem best discriminated between those with affective disorders and controls; measures of cognitive style were substantially affected by current levels of depressive symptomatology; patterns of cognitive style were similar in bipolar and unipolar disorder when current mental state was taken into account.

\section{Conclusions Those with affective} disorder significantly differed from controls on measures of cognitive style but there were no differences between unipolar and bipolar disorders when current mental state was taken into account.

Declaration of interest None.
There are few empirical studies of cognitive style, such as self-esteem and dysfunctional attitudes, in bipolar disorder (Pardoen et al, 1993; Alloy et al, 1999; Scott et al, 2000; Scott \& Pope, 2003; Lam et al, 2004). Studies have produced inconsistent findings; sample sizes tend to be small and selective, and some include non-clinical samples. The issue of whether bipolar disorder is associated with characteristic cognitive styles, and whether these factors are related to the onset or course of illness, is theoretically and clinically relevant. The aim of this study was to examine aspects of cognitive style (self-esteem and dysfunctional attitudes) in a large, representative, well-characterised and narrowly defined sample with bipolar disorder in comparison with unipolar major recurrent depression and healthy controls.

\section{METHOD}

\section{Samples}

Samples were recruited using systematic and non-systematic methods as part of our ongoing research programmes to investigate genetic and non-genetic determinants of affective disorders. Community mental health teams and lithium clinics in the West Midlands used screening methods to systematically identify individuals with major affective disorders and, with the permission of the responsible medical officer, all those meeting the entry criteria were invited to participate in the study. Advertisements for volunteers were placed in local general practitioner surgeries, local newspapers and television news programmes and circulated via patient support organisations (Manic-Depressive Fellowship and Depression Alliance).

Individuals were included if they met the following criteria:

(a) capable of giving voluntary informed written consent;

(b) aged 18 years or over; (c) met DSM-IV-TR (American Psychiatric Association, 2000), ICD-10 (World Health Organization, 1993) and Research Diagnostic Criteria (RDC; Spitzer et al, 1978) for bipolar I affective disorder or major recurrent depression; and

(d) because they were recruited for molecular genetic studies, UK/Irish White ethnicity.

Individuals were excluded if they:

(a) had only experienced affective illness in relation to, or as a consequence of, alcohol or substance misuse or dependence;

(b) had only experienced affective illness as a consequence of medical illness or medication;

(c) were an intravenous drug misuser with a lifetime diagnosis of dependency;

(d) had an organic brain disorder or other cognitive problem that impeded their ability to complete the questionnaires;

(e) declined to complete the questionnaires; or

(f) were biologically related to another study participant.

Of those suitable individuals identified via our systematic screening procedure, $44.0 \%$ refused to participate and we were unable to make contact with a further $13.9 \%$. Of those who agreed or volunteered to take part, $9.4 \%$ failed to complete the questionnaires. Our final sample comprised 118 individuals with bipolar I disorder $(47.5 \%$ recruited systematically) and 265 with unipolar major recurrent depression $(39.2 \%$ recruited systematically).

The controls were a sub-sample of participants who had originally been recruited to the GENESiS (Genetic and Environmental Nature of Emotional States in Siblings) study (Sham et al, 2000). This study recruited 34371 individuals from general practices in England and Wales. Index individuals were registered with these practices, were aged between 18 and 55 years and had no current serious medical illness or disability. GENESiS participants were approached to take part in the current study if they fell into the bottom $20 \%$ of the distribution on the Sham Composite Index of Liability to Depression and Anxiety (G; Sham et al, 2000). G comprises responses to the following self-report measures: General Health Questionnaire (GHQ-12, 12-item version; Goldberg et 
al, 1997); short form of the neuroticism sub-scale of the Eysenck Personality Questionnaire (EPQ-N; Eysenck \& Eysenck, 1975); and two sub-scales of the Mood and Anxiety Symptoms Questionnaire (MASQ; Watson et al, 1995) which measure levels of anxious arousal (MASQ-AA) and high positive affect (MASQ-HPA).

Controls were screened for a personal or family history of psychiatric illness using a semi-structured telephone interview. Of those controls who agreed to take part in the study, $3.9 \%$ failed to complete the questionnaires. Our final control sample comprised 268 individuals.

Basic demographic and clinical features of the samples are presented in Tables 1 and 2 .

\section{Assessments}

Those with affective disorders were interviewed using the Schedules for Clinical Assessment in Neuropsychiatry (SCAN; Wing et al, 1990) and psychiatric/general practice case notes were reviewed. These data were combined for each participant to form a written case vignette. Bestestimate lifetime diagnoses were made according to DSM-IV-TR, ICD-10 and RDC. The vignettes were also used to rate other key clinical variables (such as age at onset and number of episodes of illness). Each individual was diagnosed and had key clinical variables rated independently by at least two members of the research team, and consensus was reached. Interrater reliability was high. This was formally assessed using 20 cases and resulted in mean kappa statistics of $0.85,0.83$ and 0.80 for DSM-IV-TR, ICD-10 and RDC diagnoses, respectively. Mean kappa statistics for other key clinical variables ranged from 0.81 to 0.99 . Mean intraclass correlation coefficients for other key clinical variables ranged from 0.91 to 0.97 .

The following self-rated questionnaires, all with demonstrated validity and reliability, were part of a larger pack of questionnaires administered to the groups with affective disorders and the controls.

\section{Rosenberg Self-Esteem Questionnaire}

The Rosenberg Self-Esteem Questionnaire (SEQ; Rosenberg, 1965) measures trait self-esteem. It is a ten-item questionnaire comprising five positive statements (e.g. 'On the whole I am satisfied with myself') and five negative statements (e.g. 'At times
Table I Basic demographic features, Altman Self-Rating Mania Scale (ASRM) and Beck Depression Inventory (BDI) scores of those with bipolar I disorder, those with unipolar major recurrent depression and controls

\begin{tabular}{|c|c|c|c|}
\hline & $\begin{array}{l}\text { Bipolar I disorder } \\
\qquad(n=118)\end{array}$ & $\begin{array}{l}\text { Unipolar major recurrent depression } \\
\qquad(n=265)\end{array}$ & $\begin{array}{l}\text { Controls } \\
(n=268)\end{array}$ \\
\hline \multicolumn{4}{|l|}{ Gender, $\boldsymbol{n}(\%) *$} \\
\hline Male & $46(39.0)$ & $78(29.4)$ & $105(39.2)$ \\
\hline Female & $72(61.0)$ & $187(70.6)$ & $163(60.8)$ \\
\hline \multicolumn{4}{|l|}{ Age, years } \\
\hline Mean (s.d.) & 48.34 (12.09) & 48.50 (II.93) & $48.99(8.98)$ \\
\hline $95 \% \mathrm{Cl}$ & $46.14-50.54$ & $47.05-49.94$ & $47.90-50.08$ \\
\hline Range & $22-80$ & $19-85$ & $24-61$ \\
\hline \multicolumn{4}{|c|}{ Highest educational level, \% } \\
\hline CSE/O-level/GCSE & 21.8 & 24.5 & 28.5 \\
\hline A-level/HND/BTEC & 30.0 & 24.5 & 21.7 \\
\hline Degree & 17.3 & 16.7 & 16.7 \\
\hline Postgraduate degree & 9.1 & 8.6 & 16.0 \\
\hline \multicolumn{4}{|l|}{ ASRM** } \\
\hline Mean (s.d.) & $4.16(4.39)$ & $2.92(2.93)$ & 3.31 (3.34) \\
\hline $95 \% \mathrm{Cl}$ & $3.36-4.96$ & $2.57-3.28$ & $2.90-3.71$ \\
\hline Range & $0-20$ & $0-15$ & $0-13$ \\
\hline \multicolumn{4}{|l|}{$\mathrm{BDI} * * *$} \\
\hline Mean (s.d.) & $11.66(10.02)$ & $18.12(12.31)$ & $2.59(2.88)$ \\
\hline $95 \% \mathrm{Cl}$ & $9.82-13.49$ & $16.62-19.62$ & $2.24-2.94$ \\
\hline Range & $0-50$ & $0-56$ & $0-20$ \\
\hline
\end{tabular}

$* P<0.05$ unipolar disorder $v$. bipolar disorder and controls; **P $<0.003$ bipolar disorder $v$. unipolar disorder; $* * * P<0.0001$ unipolar disorder $v$. bipolar disorder $v$. controls.

Table 2 Clinical features of those with affective disorders

\begin{tabular}{|c|c|c|}
\hline & $\begin{array}{l}\text { Bipolar I disorder } \\
\qquad(n=\mid 18)\end{array}$ & $\begin{array}{l}\text { Unipolar major recurrent depression } \\
\qquad(n=265)\end{array}$ \\
\hline \multicolumn{3}{|c|}{ Episodes of mania, $n$} \\
\hline Mean (s.d.) & $7.47(6.32)$ & - \\
\hline $95 \% \mathrm{Cl}$ & $6.31-8.63$ & - \\
\hline Range & $1-40$ & - \\
\hline \multicolumn{3}{|c|}{ Episodes of depression, $n *$} \\
\hline Mean (s.d.) & $7.58(8.40)$ & $5.64(6.88)$ \\
\hline $95 \% \mathrm{Cl}$ & $6.05-9.12$ & $4.8 I-6.48$ \\
\hline Range & $0-55$ & $2-100$ \\
\hline \multicolumn{3}{|l|}{ Age at onset, years } \\
\hline Mean (s.d.) & $25.74(10.27)$ & $27.63(10.88)$ \\
\hline $95 \% \mathrm{Cl}$ & $23.84-27.64$ & $26.31-28.94$ \\
\hline Range & $\mathrm{II}-54$ & $9-60$ \\
\hline \multicolumn{3}{|l|}{ Psychosis, $n(\%) * * *$} \\
\hline Never present & $32(27.1)$ & $24 \mid(90.9)$ \\
\hline Present & $86(72.9)$ & $21(7.9)$ \\
\hline Not known & - & $3(1.1)$ \\
\hline \multicolumn{3}{|l|}{ Admissions, $n * *$} \\
\hline Mean (s.d.) & $5.5 \mathrm{I}(5.0 \mathrm{I})$ & $1.09(1.78)$ \\
\hline $95 \% \mathrm{Cl}$ & $4.58-6.45$ & $0.83-1.36$ \\
\hline Range & $0-25$ & $0-12$ \\
\hline
\end{tabular}

$* p<0.02 ; * * p<0.001 ; * * * p<0.0001$. 
I think I am no good at all'). We used the version in which each item is rated on a 1-4 scale (from strongly disagree to strongly agree for the positive items and strongly agree to strongly disagree for the negative items). Thus, scores can range from 5 to 20 on both sub-scales, with high scores on the positive sub-scale reflecting high positive self-esteem and high scores on the negative sub-scale reflecting low negative self-esteem. Combining these sub-scales produces a total SEQ score which can range from 10 to 40 , with higher total scores reflecting higher total self-esteem.

\section{Dysfunctional Attitudes Scale}

The Dysfunctional Attitudes Scale (DAS) measures underlying beliefs and attitudes. We used the 24-item version of the DAS (Power et al, 1994). Each item is rated on a 1-7 scale (totally disagree to totally agree, except for three items where the scoring is reversed). As well as a total score, which can range from 24 to 168 , the DAS gives three sub-scale scores, each ranging from 8 to 56 . The three sub-scales are achievement (example item: 'If I fail partly, it is as bad as being a complete failure'), dependency (example item: 'If others dislike you, you cannot be happy') and self-control ('I should always have complete control over my feelings').

\section{Altman Self-Rating Mania Scale}

The Altman Self-Rating Mania Scale (ASRM; Altman et al, 1997) assesses the presence and/or severity of current manic symptoms. It comprises five items scored from 0 (absent) to 4 (present to a severe degree). Total scores range from 0 to 20 .

\section{Beck Depression Inventory}

The Beck Depression Inventory (BDI; Beck $\&$ Steer, 1987) assesses the presence and/or severity of current depressive symptoms. It comprises 21 items scored from 0 (absent) to 3 (present to a severe degree). Total scores range from 0 to 63 .

\section{Eysenck Personality Questionnaire}

We used the 90-item version of the Eysenck Personality Questionnaire (EPQ; Eysenck \& Eysenck, 1975). Each item is rated either 'yes' or 'no' by respondents. The EPQ gives scores for three personality dimensions: extraversion, neuroticism (EPQ-N) and psychoticism. Scores for the EPQ-N range from 0 to 23 .

\section{Procedure}

Individuals were approached to participate in the study when they were judged by the treating medical team to be in a euthymic state. After the semi-structured interview, the questionnaires were left with participants to rate and return to the team (stamped, addressed return envelopes were provided). They were given written instructions to complete all of the questionnaires at the same time within 1 week of receiving them. If the questionnaires were not returned after 1 month, a reminder letter was sent with another copy of the questionnaires and a return envelope. If the questionnaires were still not returned after a further 2 weeks, a reminder telephone call was made.

Controls received the questionnaires via the post. Otherwise the procedure was identical to that outlined above.

This study received all necessary multiregion and local research ethics committee approval.

\section{Statistical analysis}

The three groups were compared for sociodemographic variables using the $\chi^{2}$-test or one-way analysis of variance (ANOVA), followed by post hoc comparisons using the Tukey test. Differences in key clinical variables between those with bipolar I disorder and those with unipolar major recurrent depression were examined using independent sample $t$-tests or $\chi^{2}$-tests.

The distributions of the questionnaire scores in each of the groups approximated normal, thus the three groups were compared on the ASRM, BDI and all cognitive style measures using univariate one-way ANOVAs, followed by the Tukey test. Two-way univariate analyses of covariance (ANCOVAs) were then carried out with group and gender as factors and age, ASRM and BDI scores (both separately and together) as covariates.

Binary logistic regression using forward stepwise likelihood ratio for variable selection was carried out to determine the best predictors of affective disorder versus control status. Stepwise linear multiple regression was used to examine which cognitive style variables best predicted EPQ-N score in those with affective disorders.

The Spearman rank correlation coefficient was used to examine the correlations between the cognitive style variables and key measures of past psychiatric history in those with affective disorders.

All analyses were undertaken using the Statistical Package for the Social Sciences for Windows (version 10.0.7).

\section{RESULTS}

\section{Sample characteristics}

The three groups were well matched for age and educational achievement (Table 1). Participants were predominantly female in all groups; however, there was a significantly higher proportion of females in the group with unipolar major recurrent depression $(70.6 \%)$ than the other two groups. Those with bipolar I disorder scored significantly higher on the ASRM than those with major recurrent depression, and non-significantly higher than the controls. Both groups with affective disorders scored significantly higher than the controls on the BDI, and those with unipolar major recurrent depression scored significantly higher than those with bipolar I disorder.

Clinical features of those with affective disorders are summarised in Table 2. Age at illness onset, defined as age at first clinically significant functional impairment due to affective illness, was similar for the two groups. Those with bipolar I disorder had significantly more episodes of illness and significantly more psychiatric hospital admissions than those with unipolar major recurrent depression. Nearly three-quarters of those with bipolar I disorder $(n=86)$ had experienced psychosis compared with approximately $8 \%(n=21)$ of those with unipolar major recurrent depression.

\section{Comparison of cognitive style between the groups}

Mean scores for each of the groups on each of the cognitive style measures are presented in Table 3 . There were statistically significant differences between groups on all measures. Not only did those with affective disorders differ from controls but they also showed a significantly different pattern of results. Those with unipolar major recurrent depression showed the lowest levels of self-esteem (low positive and high negative self-esteem) and those with bipolar I disorder scored significantly lower than controls and higher than those with major recurrent depression. Those with major recurrent depression also showed the highest level of dysfunctional attitudes, 
Table 3 Cognitive style scores in the three groups

\begin{tabular}{|c|c|c|c|}
\hline & Bipolar I disorder & $\begin{array}{c}\text { Unipolar major } \\
\text { recurrent depression }\end{array}$ & Controls \\
\hline Rosenberg Self-Esteem & $(n=110)$ & $(n=258)$ & $(n=264)$ \\
\hline \multicolumn{4}{|l|}{ Questionnaire } \\
\hline \multicolumn{4}{|l|}{ Total score ${ }^{i+t}$} \\
\hline Mean (s.d.) & $26.81(5.78)$ & $23.67(6.4 I)$ & $34.48(3.44)$ \\
\hline $95 \% \mathrm{Cl}$ & $25.72-27.90$ & $22.89-24.46$ & $34.07-34.90$ \\
\hline \multicolumn{4}{|l|}{ Positive sub-scale ${ }^{\dagger \dagger \dagger}$} \\
\hline Mean (s.d.) & $14.29(3.01)$ & $12.74(3.15)$ & $17.08(1.88)$ \\
\hline $95 \% \mathrm{Cl}$ & |3.72-14.86 & $12.35-13.12$ & $|6.86-| 7.3 \mid$ \\
\hline \multicolumn{4}{|l|}{ Negative sub-scale $\mathrm{e}^{\dagger \dagger \dagger}$} \\
\hline Mean (s.d.) & $12.52(3.5 I)$ & $10.94(3.70)$ & $17.40(2.2 \mathrm{I})$ \\
\hline $95 \% \mathrm{Cl}$ & $11.85-13.18$ & $10.48-11.39$ & $17.13-17.67$ \\
\hline Dysfunctional Attitudes Scale & $(n=116)$ & $(n=261)$ & $(n=265)$ \\
\hline \multicolumn{4}{|l|}{ Total score ${ }^{* * *}$} \\
\hline Mean (s.d.) & $89.78(21.91)$ & $101.15(25.59)$ & $71.69(17.21)$ \\
\hline $95 \% \mathrm{Cl}$ & $85.75-93.81$ & $98.03-104.27$ & $69.61-73.78$ \\
\hline \multicolumn{4}{|l|}{ Achievement $* * *$} \\
\hline Mean (s.d.) & $29.00(10.12)$ & $33.80(I 1.94)$ & 19.48 (7.99) \\
\hline $95 \% \mathrm{Cl}$ & $27.14-30.86$ & $32.35-35.26$ & $|8.5|-20.44$ \\
\hline \multicolumn{4}{|l|}{ Dependency** } \\
\hline Mean (s.d.) & $31.53(9.31)$ & $34.77(9.12)$ & $25.18(7.15)$ \\
\hline $95 \% \mathrm{Cl}$ & $29.82-33.25$ & $33.66-35.89$ & $24.32-26.05$ \\
\hline \multicolumn{4}{|l|}{ Self-control* } \\
\hline Mean (s.d.) & $29.24(7.95)$ & $32.58(8.78)$ & $27.04(7.52)$ \\
\hline $95 \% \mathrm{Cl}$ & $27.78-30.70$ & $31.51-33.65$ & $26.13-27.95$ \\
\hline
\end{tabular}

$* P=0.04$ unipolar disorder $v$. bipolar disorder $v$. controls; $* * P=0.002$ unipolar disorder $v$. bipolar disorder $v$. controls; $* * * P<0.0001$ unipolar disorder $v$. bipolar disorder $v$. controls.

followed by those with bipolar I disorder, followed by controls. This pattern was true for each of the sub-scales of the DAS.

These data were further analysed using ANCOVA. No significant gender by group interactions were observed, and controlling for age and ASRM scores (both separately and together) did not alter the findings. When current levels of depression, as measured by the BDI, were taken into account, no differences between the two groups with affective disorders on any of the measures emerged. However, both groups still exhibited lower levels of self-esteem and more dysfunctional attitudes (total score and achievement and dependency sub-scales) than controls. Those with major recurrent depression scored significantly higher than controls on the DAS self-control sub-scale, and those with bipolar I disorder were not significantly different from those with major recurrent depression or controls. These analyses were repeated using only those who had been recruited systematically (56 with bipolar I disorder and 104 with unipolar major recurrent depression) and an identical pattern of results emerged.

Logistic regression was carried out to determine which combination of cognitive style variables best predicted group membership (i.e. control or affective disorder). Gender, age, BDI scores, ASRM scores and all cognitive style measures were entered into the regression. The best solution correctly classified $86.3 \%$ of participants. The significant variables in this solution were $\mathrm{BDI}(\mathrm{OR}=1.23,95 \% \mathrm{CI}$ 1.15-1.31, $P<0.0001)$ and SEQ negative sub-scale $(\mathrm{OR}=0.68,95 \%$ CI $0.62-0.75$, $P<0.0001$ ).

\section{EPQ neuroticism in those with affective disorders}

In order to explore how cognitive style related to more widely used concepts of personality and vulnerability to mood disturbance, we undertook a multiple linear regression analysis in those with affective disorders with EPQ-N as the dependent variable. After controlling for BDI score, the following cognitive style variables predicted $49.5 \%$ of the variance in EPQ-N: SEQ total score (standardised $\beta=-0.34$, $P<0.0001)$ and DAS achievement score (standardised $\beta=0.20, P<0.0001$ ). These two cognitive style variables and EPQ-N were also significantly correlated with age at illness onset (SEQ total $r=0.13$, $P=0.02$; DAS achievement $r=-0.13$, $P=0.01$; EPQ-N $r=-0.12, P=0.02$ ). SEQ total score and EPQ-N were significantly correlated with number of previous episodes of depression $(r=-0.13, P=0.01$; $r=0.17, P=0.001$, respectively).

\section{DISCUSSION}

We have investigated aspects of cognitive style in individuals with bipolar I disorder, those with unipolar major recurrent depression and healthy controls. Our samples were large and powerful: post hoc power calculations, undertaken using nQuery Advisor (version 4.0), showed that on all of the questionnaire measures our sample size had $>99 \%$ power to detect at the 0.05 level the difference in means between the three groups that we demonstrated.

Those participating in this study were: (a) narrowly defined - they met lifetime diagnostic criteria according to three widely used psychiatric classification systems; (b) well characterised - illness data were collected using a validated semi-structured interview and case note review, and a range of clinical variables were rated using the consensus method, with excellent interrater reliability; (c) representative - a large percentage were systematically recruited. The controls were unaffected and selected for a low risk of developing a mood disorder. This study builds on previous work in this area which has tended to use small, selective samples and has shown inconsistent results.

\section{Comparison of those with mood disorders and healthy controls}

We have shown lower self-esteem (greater negative evaluation of self and less positive evaluation of self) and more dysfunctional attitudes (greater need for achievement, greater dependency on others and greater need for control of self) among those with 
bipolar and unipolar disorders compared with healthy controls. Our finding of abnormalities of cognitive style in those with mood disorders supports previously published work (Scott et al, 2000). We have demonstrated that when possible confounding factors are controlled for, the best predictor of whether a participant has a mood disorder or is a healthy control is the score on the negative sub-scale of the SEQ. It is interesting to note that Scott \& Pope (2003) showed that negative selfesteem was the most robust predictor of both manic and depressive relapse in those with bipolar disorder. This sub-scale should be a target for future research into cognitive style in affective disorders.

\section{Importance of measuring current mental state}

Our data show that it is essential to take account of current mental state when investigating aspects of underlying cognitive style in individuals with mood disorders. Although participants were studied when, in the opinion of the responsible medical team, they were clinically euthymic, we found significant levels of depressive symptoms. When we controlled for this in our analyses, the pattern of findings was considerably altered. This supports previous work that has demonstrated confounding effects of residual affective symptoms in those with mood disorders on measures of cognitive style and neuropsychological functioning (Ferrier et al, 1999; Clark et al, 2002; Farmer, 2004). However, it is important to note that a 12-year followup of over 100 individuals with bipolar disorder demonstrated that sub-syndromal and syndromal symptoms of depression were present for nearly $50 \%$ of the time, suggesting that this characterises the 'usual' mental state of many individuals with bipolar disorder (Judd et al, 2002). Those with unipolar and bipolar disorders with persistent residual symptoms and the associated abnormalities of cognitive style are particularly at risk of further relapse (Paykel et al, 1995; Scott \& Pope, 2003).

\section{Comparison of bipolar disorder with unipolar major recurrent depression}

When current mental state is taken into account, the measures of cognitive style employed in this study do not differentiate individuals who experience episodes of mania from those with unipolar depression.
We have not shown a pattern of cognitive style that is unique to individuals with bipolar disorder. The measures we have included indicate a non-specific, generalised pattern associated with mood disorders or psychiatric ill health in general. These findings reflect previous studies in smaller or mixed clinical and non-clinical samples that have shown similar patterns in both illnesses (Ashworth et al, 1982; Rosenfarb et al, 1998; Alloy et al, 1999; Scott \& Pope, 2003; Lam et al, 2004), and studies which have demonstrated abnormal scores on measures of cognitive style in individuals with other mental disorders, such as schizophrenia (Hollon et al, 1986; Van Os \& Jones, 2001). Much of the previous work on cognitive changes in bipolar disorder has focused on informationprocessing systems (Taylor Tavares et al, 2003). It is interesting to note that the majority of studies have shown overlapping deficits in bipolar and unipolar disorder (Bearden et al, 2001). It is difficult to find a valid explanation of how shared beliefs across mood disorders increase the risk of depressive relapse in one group but of manic and depressive episodes in the other. Scott and others have hypothesised that individuals with bipolar disorders show greater day-to-day variability in cognitive style and have a self-esteem that is more vulnerable to shift in response to external events. Such differences may emerge when cognitive style is measured in a prospective longitudinal study, and are less likely to be apparent in cross-sectional studies (Scott, 2004).

\section{Implications of the findings}

The investigation of cognitive style in bipolar disorder is of clinical relevance. For example, such factors could influence the development of psychotherapies specific to the illness, likely adherence and response to medication regimens and prognosis. We have shown that, independent of current levels of symptoms, those with bipolar disorder show a fragile cognitive style similar to those with unipolar depression. Therefore, it is not surprising that psychological treatments that are effective in depression are also helpful in reducing symptoms, improving global functioning and reducing relapse in bipolar disorder (Scott et al, 2001). Other aspects of cognition should be further investigated in bipolar disorder to refine psychological models for the development of specific targeted psychotherapies.

\section{Neuroticism and cognitive style}

We were interested to examine the relationship between measures of cognitive style and $\mathrm{EPQ}-\mathrm{N}$ in those with affective disorders. The concept of neuroticism fell out of favour for some time, but Martin (1985) described it in a clinically meaningful way, namely as a marker of vulnerability to depression and of a vulnerable cognitive style (fragile self-esteem, high levels of trait dysfunctional beliefs). This relationship between neuroticism and cognitive style appears to hold true for those with unipolar and bipolar disorder and also was related, albeit modestly, to key measures of past psychiatric history, such as number of previous episodes of depression and age at illness onset. However, the nature of our control group (i.e. they were selected partially on the basis of having low EPQ-N scores) means that we cannot explore the relationship between cognitive style and neuroticism across groups who have normal as compared with abnormal variability in mood states.

\section{Limitations}

Our study cannot determine whether the differences in cognitive style observed in those with mood disorders are a cause or a consequence of the onset or course of affective illness. It has generally been accepted that the personality trait EPQ-N, for example, is genetically determined and underlies vulnerability to develop unipolar depression (Duggan et al, 1995; Fanous et al, 2002). However, other authors (Farmer et al, 2002) have argued that elevated EPQ$\mathrm{N}$ in depression may merely reflect residual symptoms. Prospective longitudinal studies which begin in the premorbid state (e.g. using high-risk samples) are essential if we are to understand the role of cognitive style in the development of affective disorders. If aspects of cognition are shown to be markers of underlying liability to bipolar disorder, they could be useful in aetiological research, such as molecular genetic studies, and early intervention studies.

A possible limitation of our study is that we have included individuals recruited systematically (via community mental health teams and lithium clinics) and opportunistically (via advertisements). However, the analysis was repeated using only those recruited using systematic methods, and the pattern of findings was unchanged. 
To maximise our power to detect differences, we used a control group selected for low risk of developing a mood disorder ('supernormal' controls). The measures of cognitive style examined here, however, were not used to define the control group, and it is unlikely that the differences are accounted for merely by the selection of controls. Future research should aim to use unselected controls.

Our assessment tools can also be criticised. We used self-report measures of cognitive style and single subjective ratings of current manic and depressive symptoms, rather than combining them with objective investigator-rated scales. There is evidence that self-esteem in individuals with bipolar disorder is better measured by implicit means (Lyon et al, 1999) and that these individuals may show social conformism (Pardoen et al, 1993), which could bias self-report measures. However, we did not observe a significant difference between our three groups on the lie scale of the EPQ (data not shown).

In this study we have investigated only limited aspects of cognitive style in those with bipolar disorder. We have shown that although they exhibit abnormal patterns, these are not unique when compared with individuals with other mood disorders. Future studies of large, unselected samples of individuals with bipolar disorder with appropriate psychiatric and non-psychiatric controls could focus on other potentially interesting aspects of cognitive style, such as attributions, self-representations, novelty seeking traits, affective temperaments and perfectionism.

\section{ACKNOWLEDGEMENTS}

We are grateful to the Wellcome Trust and Medical Research Council for financial support. We thank Dr George Pelios for database programming, Debbie Baker and Natalie Kynes for data entry and Dr Roger Holder for statistical advice. We thank all mental health professionals who helped to recruit participants. Finally, we thank all participants who gave their time and support.

\section{REFERENCES}

Alloy, L., Reilly-Harrington, N., Fresco, D., et a (1999) Cognitive styles and life events in sub-syndromal unipolar and bipolar mood disorders: stability and prospective prediction of depressive and hypomanic mood swings. Journal of Cognitive Psychotherapy, I3 $21-40$

Altman, E. G., Hedeker, D., Peterson, J. L., et a (1997) The Altman Self-Rating Mania Scale. Biological Psychiatry, 42, 948-955.

\section{CLINICAL IMPLICATIONS}

- Those with bipolar and unipolar disorder have similar fragile self-esteem and dysfunctional beliefs.

- It is not surprising that psychological treatments that target negative cognitive style in unipolar depression are also helpful in bipolar disorder.

Unless unique aspects of cognitive style are identified in bipolar disorder, it will be difficult to develop a more specific model of psychotherapy for bipolar disorders.

\section{LIMITATIONS}

Not all patients were recruited systematically.

We relied exclusively on the use of self-report measures.

- We utilised a 'supernormal' control group.

LISA JONES, PhD, Department of Psychiatry, University of Birmingham, Queen Elizabeth Psychiatric Hospital, Birmingham; JAN SCOTT, FRCPsych, Division of Psychological Medicine, Institute of Psychiatry, London; SAYEED HAQUE, PhD, Department of Psychiatry, University of Birmingham, Queen Elizabeth Psychiatric Hospital; KATHERINE GORDON-SMITH, BSc, Department of Psychiatry, University of Birmingham, Queen Elizabeth Psychiatric Hospital, and Department of Psychological Medicine, University of Wales College of Medicine, Cardiff; JESSICA HERON, BA, SIAN CAESAR, CAROLINE COOPER, BSc, Department of Psychiatry, University of Birmingham, Queen Elizabeth Psychiatric Hospital; LIZ FORTY, BA, Department of Psychiatry, University of Birmingham, Queen Elizabeth Psychiatric Hospital, and Department of Psychological Medicine, University of Wales College of Medicine, Cardiff; SALLY HYDE, BSc, LOUISA LYON, BA, JAYNE GREENING, MRCPsych, Department of Psychiatry, University of Birmingham, Queen Elizabeth Psychiatric Hospital; PAK SHAM, MRCPsych, ANNE FARMER, FRCPsych, PETER McGUFFIN, FRCPsych, SGDP Research Centre, Institute of Psychiatry, London; IAN JONES, MRCPsych, Department of Psychiatry, University of Birmingham, Queen Elizabeth Psychiatric Hospital, and Department of Psychological Medicine, University of Wales College of Medicine, Cardiff; NICK CRADDOCK, MRCPsych, Department of Psychiatry, University of Birmingham, Queen Elizabeth Psychiatric Hospital, and Department of Psychological Medicine, University of Wales College of Medicine, Cardiff, UK

Correspondence: Dr Lisa Jones, Department of Psychiatry, Division of Neuroscience, University of Birmingham, Queen Elizabeth Psychiatric Hospital, Birmingham BI5 2QZ, UK. Tel: +44 1216782362 fax: +44 121678 235I ; e-mail: I.a.jones@bham.ac.uk

(First received 30 July 2004, final revision 8 February 2005, accepted 12 February 2005)

American Psychiatric Association (2000) Diagnostic and Statistical Manual of Mental Disorders (4th edn, text revision) (DSM-IV-TR). Washington, DC: APA

\section{Ashworth, C. M., Blackburn, I. M. \& McPherson,}

F. M. (1982) The performance of depressed and manic patients on some repertory grid measures. British Journal of Medical Psychology, 55, 247-255.

Bearden, C. E., Hoffman, K. M. \& Cannon, T. D. (200I) The neuropsychology and neuroanatomy of bipolar affective disorder: a critical review. Bipolar Disorders, 3, 106-150

Beck, A.T. \& Steer, R. A. (1987) The Beck Depression Inventory. San Antonio, TX: Harcourt Brace.

\section{Clark, L., Iversen, S. D. \& Goodwin, G. M. (2002)} Sustained attention deficit in bipolar disorder. British Journal of Psychiatry, 180, 313-319.

Duggan, C., Sham, P., Lee, A., et al (1995) Neuroticism: a vulnerability marker for depression, evidence from a family study. Journal of Affective Disorders, 35, 139-143.
Eysenck, H. J. \& Eysenck, S. B. G. (1975) Manual of the Eysenck Personality Questionnaire. London: Hodder \& Stoughton.

Fanous A., Gardner, C. O., Prescott, C. A., et al (2002) Neuroticism, major depression and gender: a population-based twin study. Psychological Medicine, 32. 719-728.

Farmer, A. (2004) Bad luck and bad genes in depression. In Behavior Genetics Principles: Perspectives in Development, Personality and Psychopathology (ed. L. DiLalla).Washington, DC: American Psychiatric Association.

Farmer, A., Redman, K., Harris, T., et al (2002) Neuroticism, extraversion, life events and depression The Cardiff Depression Study. British Journal of Psychiatry, 181, II8-122.

Ferrier, I. N., Stanton, B. R., Kelly, T. P., et al (1999) Neuropsychological function in euthymic patients with bipolar disorder. British Journal of Psychiatry, $\mathbf{1 7 5}$, 246-25I. 
Goldberg, D. P., Gater, R., Sartorius, N., et al (1997) The validity of two versions of the GHQ in the WHO study of mental illness in general health care.

Psychological Medicine, 27, 191-197.

Hollon, S., Kendall, P. \& Lumry, A. (1986) Specificity of depressive cognitions in clinical depression. Journal of Abnormal Psychology, 95, 52-59.

Judd, L. L., Akiskal, H. S., Schlettler, P. J., et al (2002)

The long-term natural history of the weekly

symptomatic status of bipolar I disorder. Archives of

General Psychiatry, 59, 530-537.

Lam, D., Wright, K. \& Smith, N. (2004) Dysfunctional assumptions in bipolar disorder. Journal of Affective Disorders, 79, 193-199.

Lyon, M., Startup, M. \& Bentall, R. (1999) Social cognition and the manic defence. Journal of Abnorma Psychology, 108, 273-282.

Martin, M. (1985) Neuroticism as a predisposition towards depression: a cognitive mechanism. Personality and Individual Differences, 6, 353-365.

Pardoen, D., Bauwens, F., Tracy, A., et al (1993) Selfesteem in recovered bipolar and unipolar out-patients. British Journal of Psychiatry, 163, 755-762.

Paykel, E. S., Ramana, R., Cooper, Z., et al (1995) Residual symptoms after partial remission: an important outcome in depression. Psychological Medicine, 25, ||7|-1180.

Power, M. J., Katz, R., McGuffin, P., et al (1994) The Dysfunctional Attitudes Scale (DAS): a comparison of forms $A$ and $B$ and proposal for a new sub-scaled version. Journal of Research in Personality, 28, 263-276.

Rosenberg, M. (1965) Society and the Adolescent SelfImage. Princeton, NJ: Princeton University Press.

Rosenfarb, I. S., Becker, J. \& Khan, A. (1998)

Dependency and self-criticism in bipolar and unipolar depressed women. British Journal of Clinical Psychology, 37, 409-4I4.

Scott, J. (2004) Cognitive theory and therapy of bipolar disorders. In Cognitive Therapy Across the Lifespan (eds M. Reisnecke \& D. Clarke). Cambridge: Cambridge University Press.

Scott, J. \& Pope, M. (2003) Cognitive styles in individuals with bipolar disorders. Psychological Medicine 33, 1082-1088.

Scott, J., Stanton, B., Garland, A., et al (2000) Cognitive vulnerability in bipolar disorders. Psychological Medicine, 30, 467-472.

Scott, J., Garland, A., Moorhead, S., et al (200I) A pilot study of cognitive therapy in bipolar disorders. Psychological Medicine, 3I, 459-467.
Sham, P. C., Sterne, A., Purcell, S., et al (2000) GENESiS: creating a composite index of vulnerability to anxiety and depression in a community-based sample of siblings. Twin Research, 3, 316-322.

\section{Spitzer, R. L., Endicott, J. \& Robins, E. (1978)}

Research diagnostic criteria: rationale and reliability Archives of General Psychiatry, 35, 773-782.

Taylor Tavares, J.V., Drevets, W. C. \& Sahakian, B. (2003) Cognition in mania and depression. Psychological Medicine, 33, 959-967.

Van Os, J. \& Jones, P. B. (200I) Neuroticism as a risk factor for schizophrenia. Psychological Medicine, 31, |129-|I34.

Watson, D., Weber, K., Assenheimer, J. S., et al (1995) Testing a tripartite model: Il. Exploring the symptom structure of anxiety and depression in student, adult and patient samples. Journal of Abnormal Psychology, 104, $15-25$.

Wing, J. K., Babor, M. D., Brugha, T., et al (1990) SCAN: Schedules for Clinical Assessment in Neuropsychiatry. Archives of General Psychiatry, 47 589-593.

World Health Organization (1993) The ICD-10 Classification of Mental and Behavioural Disorders. Diagnostic Criteria for Research. Geneva: WHO. 